Est Ag 52 (2017) 271-296

\title{
Los Tratados 26-27 sobre el evangelio de San Juan
}

Un texto difícil de la teología eucarística de san Agustín

PÍO DE Luis VizCAÍNO

Resumen: Los tratados 26-27 de san Agustín sobre el evangelio de san Juan son textos significativos para entender su teología eucarística. Es lo lógico si se tiene en cuenta que en ellos expone buena parte del discurso juánico sobre el pan de vida. Pero mientras según unos autores el teólogo de Hipona sostiene en ellos la presencia real de Jesucristo en la Eucaristía, según otros no sostiene más que una presencia simbólica. Mediante un análisis detenido del texto, el presente estudio muestra que solo cabe hablar de una presencia real que, sin embargo, integra en sí los elementos de la presencia simbólica.

PALABRAS ClAVE: sacramentum, signum, res, virtus, Christus totus, umbra, veritas, uiuificare.

Abstract: The treatises 26-27 of St. Augustine on the Gospel of St. John are significant texts to understand his Eucharistic theology. This is so because in them he exposes much of the Johannine discourse on the bread of life. But while for some authors the theologian of Hippo holds in them the real presence of Jesus Christ in the Eucharist, for others he maintains only a symbolic presence. Through a careful analysis of the text, the present study shows that it is only possible to speak of a real presence which, nevertheless, integrates in it the elements of the symbolic presence.

KEYWORDs: sacramentum, signum, res, virtus, Christus totus, umbra, veritas, uiuificare. 


\section{LOS «TRATADOS SOBRE EL EVANGELIO DE SAN JUAN»}

Los evangelios sinópticos nos dejaron cada uno su relato de la institución de la eucaristía (Mt 22,26-28; Mc 14,22-25; Lc 22,19-20); san Pablo también nos dejó el suyo (1 Co 11,23-27; cf. también 1 Co 10,16-17; 11,1733). San Juan, en cambio, nos dejó el discurso del pan de vida (Jn 6,34-71). De todos estos textos san Agustín solo comentó el último. Su comentario lo conservamos en la obra que lleva por título Tratados sobre el evangelio de san Juan. El número de esos Tratados asciende a 124; una parte de ellos ciertamente predicados (1-35), y el resto con toda probabilidad dictados (36124). Concluir el proyecto le llevó bastantes años: habiéndolos comenzado en el año 406, no los concluyó antes del 420. Dado el modo de actuar del pastor de Hipona, esta circunstancia hace que la perspectiva teológica que orienta el comentario se vaya modificando en línea con los errores doctrinales a que tenía que hacer frente: en los primeros tratados su primera preocupación es refutar con los textos del evangelio al donatismo; luego su preocupación fundamental gira hacia el arrianismo y, en menor medida, también hacia el pelagianismo. Los que nos van a ocupar, los mencionados Tratados 26 y 27, se asume que fueron predicados en el año 414, un momento especial en la vida de Agustín como teólogo: ya se encuentra plenamente inmerso en la controversia pelagiana, pero su reflexión todavía recibe un notable influjo del conflicto con los donatistas.

\section{Los TRATADOS 26 y 27}

Comentar todo el discurso de un tirón, aun limitándose a la parte específicamente eucarística, habría excedido las fuerzas tanto del comentador como de sus oyentes. Por eso el predicador optó por exponerlo en tres Tratados, el 25, 26 y 27, aunque a nosotros nos interesan únicamente los Tratados 26 y 27, y el primero solo a partir del parágrafo 10 . En efecto, en el Tratado 26 el predicador expone Jn 6,41-59, texto que cabe dividir en dos partes, cada una de las cuales contiene una objeción de los judíos y la réplica de Jesús. La primera abarca los versículos 41-51, de los que dos (vv. 41-42) refieren lo dicho por los judíos, y los restantes (vv. 4351), la respuesta de Jesús. En el comentario agustiniano ocupa los parágrafos del 1 al 13. La segunda parte se extiende del versillo 52 al 591, de

${ }^{1} \mathrm{Al}$ versículo 53 hace referencia de paso ya en el parágrafo 13, pero su explicación es objeto del parágrafo 14 . 
los que uno (v. 52) refiere la dificultad expresada por los judíos, y los restantes (vv. 53-59), la respuesta de Jesús. En el comentario agustiniano se ocupan de ella los parágrafos 13-20. El Tratado 27 continúa la exposición de lo que resta del capítulo, desde las dificultades que las palabras de Jesús suscitaron específicamente a muchos de sus discípulos hasta el final (Jn 6,60-71).

Ambos Tratados son bien conocidos de quienes estudian la teología eucarística agustiniana, sobre todo por la dificultad de interpretación de algunos de sus textos. Estos no han sido ajenos a las discusiones entre teólogos que, desde el s. IX hasta nuestros días, ha provocado el pensamiento del santo. La más relevante ha sido sin duda la que versaba sobre el tipo de presencia de Cristo que el santo admite en la eucaristía: si solo real -su cuerpo y sangre-, o solo simbólica -su cuerpo eclesial-, o la una y la otra ${ }^{2}$, o en un aspecto uno y en otro otra ${ }^{3}$. Una discusión que no procede relegar al pasado, puesto que aún se mantiene viva en la actuali$\mathrm{dad}^{4}$. Baste lo dicho como ambientación.

2 "From the nineteenth century beginnings of critical history of dogmatic theology, scholarly opinion, for the most part, has held that Augustine never fully affirmed that the humanity assumed by the Word is communicated in, and by, the consecrated elements of the Eucharist", (KILMARTin, Edward J., SJ, "The Eucharistic Gift: Augustine of Hippo's Tractate 27 on John 6,60-72", en HunTer, David G. (ed.), Preaching in the Patristic age: Studies in honor of W.J. Burghardt, Paulist Press, New York 1989, 162-182: 162. Para una síntesis de los argumentos a favor de una u otra tesis, cf. JACKSON, Pamela, "Eucaristía", en Fitzgerald, Allan (ed.), Diccionario de san Agustín, Ediciones Monte Carmelo, Burgos 2001, 542-548: 546-548.

${ }^{3}$ C. Rochetta, por ejemplo, sostiene que Agustín se mueve entre realismo y simbolismo. En cuanto obispo, es fiel a la concepción de la Iglesia sobre la presencia real de Cristo en la eucaristía, pero en cuanto teólogo se esfuerza por interpretar el misterio, introduciendo aportaciones personales que conllevan elementos de debilitamiento de la doctrina eucarística (Florio, Mario - Rochetta, Carlo, Sacramentaria Speciale I. Battesimo, confermazione, eucaristia, Edizioni Dehonianae, Bologna 2004, 246.

4 Al respecto, cf. Kilmartin, Edward J., SJ, "The Eucharistic Gift", y también su obra The Eucharistic in the West. History and Theology, The liturgical Press, College Ville, Minnesota 1998. Asimismo Burns, James Patout, "The Eucharist as the Foundation of Christian Unity in North African Theology", en Augustinian Studies 32 (2001) 1-23, 5-13. Ambos autores piensan que en estos Tratados san Agustín sostiene una presencia simbólica, es decir, referida al cuerpo eclesial de Cristo, en oposición a M.- Fr. Berrouard. Este sabio dominico es quien más se ha ocupado de ello. A las abundantes y eruditas notas que acompañan su traducción en el vol 72 de la Bibliotèque Augustinienne, hay que añadir estos otros estudios: "Pour une réflexion sur le «Sacramentum» augustinien. La manne et l'Eucharistie, dans le «Tractatus XXVI, 11-12 in Iohannis Evangelium»", en Forma futuri. Studi in onore del Cardinale Michele Pellegrino, Bottega d'Erasmo, Torino 1975, 830-844; "L'être sacramentel de l'eucharistie selon saint Augustin. Commentaire de Jean VI, 60-63 dans le Tractatus XXVII, 1-6 et 11-12 in Iohannis Evangelium", en Nouvelle revue théologique 99 (1977) 702-721. 
En las páginas que siguen presentamos primero el criterio conforme al cual juzgamos que se han de interpretar ambos textos agustinianos y a continuación lo interpretamos en conformidad con él. Su aplicación permitirá advertir el error de quienes, apoyándose en determinados pasajes, concluyen que san Agustín admite únicamente una presencia simbólica de Cristo en el sacramento de la eucaristía. El estudio se centra exclusivamente en los textos señalados y son interpretados desde ellos mismos, prescindiendo de otros textos del santo que se colocan en la misma línea y utilizan el mismo lenguaje.

\section{Jesucristo es la Vida eterna}

Según san Juan, los judíos murmuraban de Jesús porque había dicho que él era el pan bajado del cielo, extrañados de que osara afirmar tal cosa, pues conocían a su padre -José- y a su madre (vv. 41-42). De la respuesta de Jesús cabe resaltar este versículo: «Nadie puede venir a mí, si el Padre que me ha enviado no lo atrae» (v. 44a). Así han aparecido los dos protagonistas, Jesucristo y el Padre, que van a determinar la estructura del comentario que sigue. El Padre está en el centro de los primeros versículos (vv. 44-47); el Hijo (Jesucristo), en el centro de los siguientes (vv. 47-51).

Lo primero que Jesucristo afirma de sí es esto: «En verdad os digo: el que cree en mí tiene vida eterna» (v. 47). Según san Agustín, Jesús pretende revelar qué es él; que él, en cuanto Dios verdadero, es la Vida eterna, por lo que tenerle a él equivale a tener la vida eterna. Solo que la Vida eterna quiso morir y, para poder hacerlo, asumió la carne humana, aunque siguiendo una vía distinta a la de los demás hombres. El hecho es que la Vida asumió la muerte para que la Vida diera muerte a la muerte. En efecto, la Vida eterna es la Palabra que en el principio existía en Dios, que era Dios, y la vida era la luz de los hombres (cf. Jn 1,1). Jesucristo mismo, en cuanto vida eterna, otorgó la vida eterna también a la carne que había asumido. Vino a morir, pero resucitó al tercer día. El predicador ha contemplado la doble realidad, divina y humana, de Jesucristo. Propiamente, en origen, la Vida es lo oculto de él, su condición de Palabra de Dios, no lo que saltaba a la vista, la carne; no obstante, su carne posee también la vida eterna por don de la Palabra que la asumió. La prueba es que resucitó, señal de que la muerte fue destruida $(26,10)$. La idea de que él es la Vida y el modo cómo va a hacer partícipe de ella a los 
hombres marca el discurso de Jesús y, consiguientemente, el comentario de Agustín.

\section{El maná y el altar del Señor, sacramentos por los que se participa de la Vida}

A continuación, Jesús se autopresenta como el pan de vida (Jn 6,48). Después de recordar a los judíos que sus padres comieron el maná en el desierto, pero murieron (Jn 6,49), vuelve sobre sí mismo aclarando la afirmación anterior: él es pan que ha descendido del cielo para que quien lo coma no muera (Jn 6,49-50). Dado que el maná había descendido del cielo (Éx 16,4), de forma implícita Jesús se ha equiparado a un nuevo maná.

Como el predicador cristiano lee el Antiguo Testamento con la mirada puesta en el Nuevo, el alimento del maná le evoca el alimento del altar. Dada la íntima relación entre una y otra realidad, ve en ambas un sacramento y desde esta categoría las interpreta. De hecho, después de indicar por qué murieron los padres de los judíos, a pesar de haber comido el maná, el predicador añade: «En efecto, también nosotros (los cristianos) recibimos un alimento visible, pero el sacramento es cosa distinta de él y lo mismo la virtud (virtus) del sacramento» $(26,11)$. La observación de que el signo visible -en el texto, el alimento visible- no se identifica con el sacramento es un reconocimiento implícito de que en el sacramento se da siempre un signo; asimismo, en la indicación de que el sacramento es algo distinto del signo sensible es fácil advertir una referencia a la realidad (res) que él oculta, sin la que tampoco hay sacramento. Se trata de conceptos básicos de la concepción sacramentaria agustiniana que él refiere al maná y al sacramento del altar: un signo (visible) $(26,12)$, una realidad invisible significada por él (res) $(26,12)$ y una virtud o efecto (virtus) (26,11.12). Peculiaridad de ambos sacramentos es que son diversos en cuanto signos, iguales en cuanto a la realidad significada (res) y también en la virtud (virtus), aunque la igualdad no sea plena.

Distintos son, pues, los signos sacramentales (signa): el maná (y el agua sacada de la roca $^{5}$ ) en el primer caso, el pan y el vino en el segundo. En ambos casos, un alimento visible, pero uno el de los judíos y otro el de los cristianos.

5 Para mantener el paralelismo con el sacramento del altar cuyos signos visibles son el pan y el vino -comida y bebida-, aunque el texto evangélico solo contempla el maná -comida-, el predicador recurre a 1 Cor 10, para introducir también el agua -bebida-. 
La realidad (res), en cambio, es igual: la misma comida en cuanto a su naturaleza espiritual y la misma bebida en cuanto a su naturaleza espiritual de que habla San Pablo (1 Cor 10,1-4), las mismas para los judíos entonces y para los cristianos ahora, es decir, Jesucristo, que se ofrece como comida y como bebida. Con referencia al pan y vino eucarísticos, el predicador no lo argumenta o porque no lo cree necesario, o porque sirve el argumento a fortiori. En cambio, sí siente la necesidad de hacerlo con referencia al maná y al agua. Como prueba le sirven las palabras del Apóstol según las cuales (nuestros padres) bebían de la roca espiritual que los seguía, roca identificada por él con Cristo (1 Cor 10,4). Aunque el texto habla solo del agua, el santo lo refiere también al maná6: de Cristo llega tanto el pan (es decir, el maná) como la bebida (Inde panis, inde potus). La realidad (res) de ambos sacramentos es, pues, Jesucristo, en su condición de comida y de bebida. Pero aquí acaba la igualdad, pues una diferencia ulterior hace distintos los sacramentos: los judíos encontraban a Cristo en la piedra que lo significaba; los cristianos lo encuentran en el pan celeste $(\mathrm{Jn} 6,50)(26,11)^{7}$. Si bien la realidad (res) de ambos sacramentos es Cristo, pan vivo bajado del cielo, en el maná está en cuanto sombra (umbra), en el altar ya en su verdad (veritas) $(26,13)$. Importante es señalar que la realidad (res), no está solo «significada» por los diferentes signos sacramentales, sino efectivamente presente, aunque de diferente modo en uno y otro sacramento. La prueba viene de la virtus del sacramento: si el santo entendiese bajo «sacramento» solo el signo visible, no habría podido atribuirle la virtus que le atribuye, pues ni el maná ni el agua, ni el pan ni el vino por sí mismos pueden otorgar la vida eterna. Por tanto, el sacramento de que aquí habla Agustín incluye el signum y la res de la tradición teológica posterior.

La virtud (virtus) de los dos sacramentos es igual también: la vida, pues la realidad (res) es Jesucristo, pan descendido del cielo para que quien lo coma no muera (Jn 6,50). Se trata de una virtud (virtus) espiritual, que, por eso mismo, permite entender la realidad (res) «significada» por los signos visibles ${ }^{8}$. Es decir, hasta tal punto depende de la realidad

${ }^{6}$ En realidad, no necesitaba prueba alguna, dado que Jesús mismo se había presentado a sí mismo como el pan descendido del cielo (Jn 6,51).

${ }^{7}$ Esto es, el Cristo verdadero, en su condición de Palabra y en su condición de carne $(26,12)$. Según M.-Fr. Berrouard en estas palabras no hay alusión alguna a la eucaristía, pues el santo no hace sino oponer el signo y la realidad ("Pour une réflexion", 438). Pero lo uno no tiene por qué excluir lo otro.

${ }^{8}$ El maná por una parte, y el pan y el vino por otra significan lo mismo por su virtud (virtus) espiritual (Aliud illi, aliud nos, sed specie visibili, quod tamen hoc ídem (la bebida espiritual) significaret virtute spiritali) $(26,12)$. 
(res) la virtud (virtus) que esta manifiesta aquella. Sin afirmación explícita, esto parece decir el predicador: si la virtud (virtus) es la vida eterna -no morir a nivel espiritual, no físico- la realidad (res) solo puede ser la Vida eterna, Cristo. Pero esa virtud (virtus), ese efecto, no se produce de forma automática, ni en el sacramento del maná, ni en el sacramento del altar de Dios, sino que requiere determinadas condiciones $(26,12)$.

A san Agustín, en otro tiempo gramático de profesión, no se le escapa el modo diferente de expresarse de Jesús y de san Pablo. Refiriéndose uno y otro a los judíos durante la travesía del desierto, Jesús habla de «vuestros padres» (Jn 6,49.58) y san Pablo, de «nuestros Padres»; mientras Jesús afirma que (todos) murieron, san Pablo afirma que la mayoría no fueron del agrado de Dios y quedaron postrados en el desierto (1 Cor 10,5). A partir de aquí, san Agustín distingue entre los padres de los judíos -los judíos que murieron en el desierto que no agradaron al Señor- y los padres de los cristianos -los judíos que no murieron y que le agradaron, entre los que cuenta a Moisés, a Aarón, a Fineés, etc-. El predicador puntualiza que no se trata de una muerte física, porque ésta la padecieron todos, sino de la muerte espiritual con que atemoriza el Señor. A la pregunta de por qué murieron unos y no murieron otros, responde: los primeros murieron «porque creían lo que veían, pero no entendían lo que no veían»; es decir, porque para ellos no existía más que lo que percibían los ojos, el alimento material, sin entender lo que ocultaba. Creyeron que todo se reducía a satisfacer el hambre del cuerpo. Porque no creyeron que aquel alimento era signo de Cristo, no entendieron que otorgaba otro tipo de vida distinta de la física y por ello no la alcanzaron. Más adelante añadirá también una razón moral: el haber murmurado contra Dios $(26,11)$. Los segundos no murieron porque trascendieron lo que veían y entendieron la condición espiritual (spiritaliter) de aquel alimento, como tal (spiritaliter) sintieron hambre de él, como tal (spiritaliter) lo gustaron para que, como tal (spiritaliter), los saciase ${ }^{9}$. En

${ }^{9}$ El sentido del adverbio en este pasaje cabe deducirlo del mismo texto juánico leído en su totalidad. Jesús comienza presentándose como el pan de vida $(\mathrm{Jn} 6,49)$ y acaba diciendo que es el Espíritu quien da vida (Jn 6,63). Aunque el exégeta solo se ocupa de este versículo cuando el desarrollo del comentario llega a él, es probable que esté en su mente desde el principio. De ahí que interprete la comida del maná y del sacramento del altar desde la perspectiva del Espíritu: fuera de él no hay vida, con él sí la hay. Por tanto, comer el pan celeste «espiritualmente» significa comerlo de forma que posibilite recibir el Espíritu (Io. eu. tr. 27,11). «Espiritualmente» haría referencia directa más al Espíritu divino, que al espíritu humano. El Sermón 131, manifiesta de forma clara esta realidad al vincular el comer y beber «espiritualmente» con Jn 6,63: «... el cuerpo y la sangre de Cristo será vida para cada uno, si lo que se toma visiblemente en este sacramento, se come y se 
la terminología sacramental agustiniana: porque descubrieron la realidad espiritual (res) oculta, pero presente, en aquellos signos sacramentales y de ella tuvieron hambre, y de ella gustaron para ser saciados ${ }^{10}$. En un segundo momento, el predicador se fija en los cristianos. Después de indicar que también ellos tienen hoy un alimento visible -el pan y el vino-, lo distingue, como ya indicamos, del sacramento mismo y de su virtud (virtus), para pasar a hablar de esta. Que identifica esa virtud (virtus) con la vida se deduce de la afirmación siguiente: «iCuántos toman ese alimento del altar y mueren, y mueren precisamente por recibirlo!», aduciendo la advertencia de san Pablo (1 Cor 11,29) y el caso de Judas en quien, nada más recibirlo, entró el enemigo $(22,3)$. Al afirmar que el bocado del Señor no fue para él veneno, el predicador indica directamente que la muerte no se la produjo lo que comió en la mesa del Señor e, indirectamente, sostiene que la vida la aporta lo que en tal mesa se come. Por supuesto, esa comida reclama unas condiciones de fe y morales para que pueda otorgar vida. La fe está presupuesta en la exhortación a comer el pan celeste (Jn 6,50.51) spiritaliter, es decir, reconociendo lo que se toma en la mesa como ese pan celeste, no como simple pan y vino; las condiciones morales, en la exhortación a acceder al altar sin haber dañado a nadie (innocentia) y habiendo perdonado, conforme a la petición del Padrenuestro (Mt 6,12) (26,11). En el trasfondo de estas exigencias morales hay exigencias eclesiales.

\section{Participación en la Vida eterna participando del sacramento del altar}

Concluida la exposición de Jn 6,49 que le ha dado la oportunidad de presentar al maná (y el agua salida de la roca), y el pan y el vino como sacramentos - cada uno con su diferente signo sensible (signum), su igual (res) y virtud (virtus)-, el predicador continúa con la exposición del texto de san Juan. En el versículo siguiente lee: Este es el pan que ha descendido del cielo, para que si alguien come de él no muera (Jn 6,50). En su comentario, explica que en esas palabras de Jesús hay que entender la

bebe en su misma verdad (de cuerpo y sangre del Señor) pensando en recibir el Espíritu (spiritaliter). De hecho hemos oído al Señor mismo decir: El Espíritu es el que da vida, la carne no sirve de nada (Jn 6,63)» (s. 131,1).

10 Adviértase que, con referencia al sacramento que era el maná, la virtud (virtus) no la hace depender del sacramento mismo sino de algo humano como es el hecho de haber entendido, deseado, gustado y saciado de lo que se ocultaba bajo aquel signo. 
virtud (virtus) del sacramento en sí, no del elemento visible del sacramento ${ }^{11}$; que se trata de algo que recibe quien lo come en su interior, no en su exterior; quien lo come entendiendo lo que significa (corde), no quien lo mastica con los dientes $(26,12$; cf. 27,3). En ambos casos la primera opción se refiere al sacramento sin más -relacionado con la vida eterna-, y la segunda al «sacramento visible»-relacionado con la vida temporal-. Con otras palabras, el efecto (virtus) señalado no es fruto de la manducación física, no obstante que deba tener lugar, sino de recibirlo sabiendo lo que se recibe (corde $)^{12}$. Lo que nos importa aquí es que con el texto citado ha vuelto a señalar cuál es la virtud (virtus) del sacramento: evitar la muerte eterna, no la temporal, o, en positivo, otorgar la vida, también la eterna.

Jn 6,50 consta de dos partes. En la primera (Jn 6,50a), la autopresentación de Jesús introduce, respecto a las anteriores, un elemento nuevo de gran valor para la exposición que va a hacer el obispo de Hipona: él es el pan vivo bajado del cielo, y vivo precisamente por descender del cielo. Aunque del cielo descendió también el maná, este representaba solo la sombra; en cambio, el que ahora se autopresenta, Cristo, representa la verdad $(26,13)$. A partir de este momento, el comentario del santo deja de lado «la sombra», el maná, para ocuparse únicamente de «la verdad», Cristo encarnado. La segunda parte del versillo -Si alguien come de este pan vivirá eternamente, y el pan que yo le daré es mi carne por la vida del mundo (Jn 6,50b) - y el siguiente -y el pan que yo le voy a dar es mi carne por la vida del mundo (Jn 6,51)- recuperan la idea de la vida, presentada antes como virtud (virtus) del sacramento, pero ahora $-\mathrm{y}$ aquí está la novedad y el problema- vinculada a comer su carne. El pan vivo pasa a ser la carne de Cristo.

La continuación del discurso de Jesús se centra en la idea de que comer su carne y beber su sangre aporta vida, vida que, pocos versículos después, se especificará como vida eterna (Jn 6,54). En la terminología sacramental del santo, equivale a decir que esa parte del discurso contiene la virtud (virtus) del sacramento -no del signo sacramental-. Y esa es la clave desde la que hay que interpretar la exposición que el predicador

11 Parece claro que en la frase el predicador usa el término «sacramento» en dos sentidos: en el primero, en cuanto signo visible portador de un significado espiritual; en el segundo, solo en cuanto signo visible. El que haya añadido el adjetivo "visible" es revelador.

12 Estamos habituados a relacionar el corazón con la parte afectiva del hombre, pero en Agustín como ya en la tradición bíblica, al corazón se le relaciona igualmente con la inteligencia. 
va a hacer de Jn 6, 51-71. En consecuencia, si hay que interpretarla en clave de virtud (virtus) del sacramento, es inútil tratar de identificar desde ella la realidad (res) del mismo, aunque pueda aparecer de soslayo. Del comentario agustiniano a esos versículos no cabe extraer, pues, conclusiones sobre el problema secular de si el teólogo de Hipona es defensor del simbolismo o del realismo eucarístico. Tal cuestión pertenece propiamente al ámbito de la realidad (res) del sacramento.

\section{a) Aspectos contemplados en relación con la virtud (virtus) del sacra- mento del altar}

A punto de poner término a su comentario al discurso del pan de vida, el predicador presenta en síntesis los aspectos que ha considerado al interpretar las palabras de Jesús sobre su carne y su sangre ${ }^{13}$. Señalamos tres que interesan a nuestro objetivo: a) explicación del rechazo que suscitaron en los judíos y discípulos; b) la promesa de la vida eterna, vinculada a la acción de comer la carne y beber la sangre de Jesús efectivamente; c) la prueba de que efectivamente tiene lugar esa doble acción: participar del Espíritu Santo $(27,11)$. Ni el orden en que los acabamos de presentar es el que aparece en la síntesis agustiniana, ni la exposición que de ellos hace el predicador tiene carácter sistemático. Su comentario no es lineal porque, al acercarse al texto como exegeta o, si se quiere, como gramático, estaba sometido al orden de ideas que le sugería el texto de san Juan, que seguía paso a paso. Tanto el orden como el modo como son presentados son nuestros.

a) Explicación del rechazo que las palabras de Jesús suscitaron en los judíos y en muchos de sus discípulos (Jn 6,52; 6,60)

Según el relato evangélico, nada más afirmar Jesús que iba a dar su carne para la vida del mundo (Jn 6,51), comenzaron los judíos a discutir entre sí. Incrédulos, se preguntaban cómo (quomodo) podía ser eso posible (Jn 6,52). Más adelante, refiriéndose ya específicamente a los discípulos de Jesús, el evangelista afirma que muchos de ellos reaccionaron considerando duras tales palabras y hasta escandalizándose (Jn 6,60). Tal reacción se explica, dice el predicador, si se tiene en cuenta que, de forma caprichosa y al modo humano, entendían que Jesús podía o se disponía a

\footnotetext{
13 Kilmartin supone una equivalencia entre la carne y sangre de Cristo y el cuerpo (eclesial) de Cristo difícil de aceptar ("The eucharistic Gift", 178).
} 
distribuir como troceada a quienes creyeran en él la carne de que estaba revestida la Palabra $(27,2.3)$. De forma ya más concreta, expone que entendieron que les iba a dar su carne como la de un cadáver desgarrado o como se vende en el mercado, es decir, descuartizada, no como animada mediante el espíritu $(27,5)$.

Para sostener la veracidad de las palabras de Jesús, esto es, que su carne y su sangre aportan la vida eterna a quienes la comen y la beben, el predicador siente la necesidad de rebatir la concepción de los escépticos. Para hacerlo sigue diversas vías. La primera consiste en indicar que ese modo de entender tiene su origen en la condición carnal tanto de los judíos como de los discípulos que se escandalizaron: siendo ellos carne (=personas carnales) no podían entender que Jesús llamase carne al pan ${ }^{14}$. La verdad, en cambio, es que él llama carne a algo distinto de lo que sus oyentes entendían bajo esa palabra; mientras ellos pensaban en algo muerto, Jesús contemplaba algo vivo $(26,13 ; 27,1)$, desde el momento que la ha identificado con el «pan vivo descendido del cielo» (Jn 6,51). El problema de judíos y discípulos era que no creyeron que Jesús estaba afirmando algo fuera de lo común y que con aquellas palabras encubría alguna gracia $(27,2)^{15}$; o, con expresión más genérica, siempre del predicador, que entendieron carnalmente lo espiritual $(27,11)$. Y ya lo afirma san Pablo: pensar con criterios carnales lleva a la muerte (Rom 8,6) $(27,1)$, incluso si se trata de la carne de Cristo. Es lo que les había pasado a sus antepasados en el desierto (cf. 26,11).

Luego el predicador mostrará que la comprensión de judíos y discípulos antes referida es errónea. Lo hace poniendo de relieve la unidad del cuerpo y de la sangre de Cristo que resulta de las mismas palabras de Jesús: Quien come mi carne y bebe mi sangre tiene vida eterna (Jn 6,54), unidad que presenta como realidad (res) del sacramento que se prepara en la mesa del Señor $(26,15)^{16}$ y que hace posible que el que come su

14 Jesucristo había hablado repetidamente de pan: "pan de la vida" (v. 48), "pan que desciende del cielo" (v. 50) y "pan vivo descendido del cielo" (v. 51a) y, de buenas a primeras, lo identifica con su carne: "el pan que yo voy a dar es mi carne" (v. 51c).

15 A Kilmartin le parece que esta gracia remite al don de que ha hablado en el parágrafo anterior ("The eucharistic Gift", 165). Pero allí el don es claramente la carne del Señor, en principio algo visible, mientras que aquí habla de una gracia oculta. En cuanto al texto paralelo de 27,11 , la gracia no se identifica con la carne y sangre de Cristo, sino con el efecto de su distribución por parte del Señor.

16 En línea con la interpretación que ha dado del texto que precede inmediatamente (cf. nota 13), Kilmartin afirma: "De la participación en este don eucarístico, esto es, la 'unidad del cuerpo y sangre de Cristo' resulta una profundización de la vida en el cuerpo" ("The eucharistic Gift", 168). Luego concluye: "En consecuencia, vive del Espíritu de 
carne y bebe su sangre participe del Hijo $(26,19)$. Esa unidad, por otra parte, está implícita en la primera parte de la respuesta de Jesús mismo a la objeción de sus discípulos, consistente en remitirles a su ascensión: si llegaran a verle subir a donde estaba antes $(\mathrm{Jn} 6,62)^{17}$ y si lograban entender lo que eso significaba, verían desaparecer la causa de su escándalo: advertirían que subía al cielo íntegro ${ }^{18}$, no descuartizado, de donde podían sacar la conclusión de que el cuerpo de Cristo no se distribuye del modo que ellos piensan y su gracia -entendemos aquí su carne y su sangre- no es algo que se consume a bocados $(27,3)^{19}$.

Pero la segunda parte de la respuesta de Jesús parece dar la razón a quienes no le creían: si la carne no sirve para nada, ¿cómo va a poder la carne de Cristo otorgarles la vida eterna? El predicador siente la necesidad de matizar las palabras de Jesús, señalando que la carne que no sirve es la carne sola, privada del espíritu. Animada por el espíritu la carne tiene valor, afirmación que prueba con varios ejemplos, uno consistente en una comparación (la ciencia acompañada de la caridad [1 Cor 8,1])20, y dos que van al grano: la carne de Cristo y la de los apóstoles $(27,5)$. ¿Cómo puede sostenerse que la carne de Cristo no sirve para nada? Si así fuera, la Palabra no se habría encarnado; además, Cristo nos fue de

Cristo quien obra (works) en el cuerpo de Cristo" (ibid.). Pero el autor no ha explicado a qué se refiere el santo con "la unidad de la carne y de la sangre de Cristo", la realidad (res) del sacramento. Él parece suponer que es el cuerpo eclesial de Cristo, pero eso necesita ser probado. Aquí damos otra interpretación.

${ }^{17}$ La referencia aquí a la ascensión puede tener relación con la afirmación de Jesús de que él era el pan vivo bajado del cielo (Jn 6,51).

18 Cf. Berrouard, Marie-François, "L'integrité de la nature humanine du Christ après sa résurrection", en Bibliothèque Augustinienne. Oeuvres de Saint Augustin 72, Paris 1977, 827-828, nota complementaria 67.

19 En virtud del paralelismo del texto, Kilmartin equipara "su cuerpo" con "su gracia". Poniendo el texto en relación con 27,1 , que habla de la distribución de su don (su carne), y con 27,11 donde se habla de la gracia de la distribución (de su carne y sangre), concluye que san Agustín no parece haber ido más allá de la idea de que el don de la eucaristía es una más profunda inserción en el cuerpo de Cristo, la Iglesia santa: el único punto mencionado explícitamente en 26,14-15 ("The eucharistic Gift", 165). Pero, a poco que se consideren los tres pasajes no son equiparables. De una parte, no es lo mismo la distribución de un don que la gracia asociada a esa distribución; de otra, el que dos términos fundamenten un paralelismo no implica que se identifiquen; en tercer lugar, no hay razón para pensar que con "cuerpo" aquí el santo se refiera al cuerpo eclesial. Por otra parte, no vemos la lógica de la conclusión del autor, aunque admitimos que don de la eucaristía es una más profunda inmersión en el cuerpo de Cristo, la santa Iglesia, bien expresada en 26,14-15. Solo que esto es consecuencia de algo previo, la relación personal con Cristo. Una exposición más amplia de la interpretación dada por los discípulos a las palabras de Jesús puede leerse en BERROUARD, "L'être sacramentel", 703-707.

20 Téngase en cuenta que san Agustín considera la caridad como don del Espíritu (Rom 5,5), por lo que sirve adecuadamente de comparación: el Espíritu vuelve útil la ciencia. 
gran provecho gracias a su carne. Por medio de ella el espíritu actuó a favor de nuestra salvación ${ }^{21}$. ¿Y cómo no nos sirvió la carne de los apóstoles, si por medio de ella nos han llegado el anuncio evangélico y la Escritura? Se trata siempre de obras de la carne, aunque impulsada por el espíritu $(27,5)$. En efecto, afirmar de forma absoluta que la carne no sirve para nada atentaba contra un fundamento de la fe, como es la encarnación del Hijo de Dios. Jesús no hablaba, pues, de su carne tal como la imaginaban los escépticos. Porque no creyeron quién era Jesús, no entendieron su don. Lo contrario de los Doce, en representación de los cuales habló Pedro, que creyeron que Jesús era el Mesías, el Hijo de Dios, y por eso creyeron que tenía palabras de vida eterna (Jn 6,69). Esta confesión la interpreta así el predicador: creyeron que Jesús era la Vida eterna en persona y que, por ello, entendieron que en su carne y en su sangre les daba lo que él era, la Vida $(27,9)$. No hay objeto para la inteligencia, si antes no hay objeto para la fe. La fe les unió a Jesús, y luego pudieron entender que la vida les llegaba de él $(27,7)$. Traspasado a nomenclatura sacramentaria, quien cree que en la eucaristía se ofrece Cristo, el pan de vida (res del sacramento), entiende que la eucaristía otorga la vida eterna (virtus del sacramento).

b) La promesa de la vida eterna, vinculada a la acción de comer la carne y de beber efectivamente la sangre de Cristo, esto es, a permanecer en él (Jn 6, 53-54.56)

La ignorancia de los escépticos, judíos solo o también discípulos, no se limitaba al cómo referido al pan, sino también al cómo referido a quien lo come $(26,15)^{22}$. Antes de indicarlo, Jesús no hace sino reafirmarse en lo dicho: si no comen su carne y beben su sangre, no tendrán vida en ellos (Jn 6,54). De igual manera, antes de referirse al modo cómo se ha de comer la carne y beber la sangre de Cristo se detiene en mostrar en qué coinciden y en qué difieren el alimento con que se sustenta la vida temporal y el alimento que es la carne y la sangre de Jesucristo: ambos son necesarios para sustentar respectivamente las dos vidas del hombre,

${ }^{21}$ Kilmartin interpreta que el santo habla del Espíritu divino puesto que se trata de la vida divina. Pero no lo vemos tan seguro, pues está hablando simplemente de la actividad de seres humanos mediante los cuales ha llegado a los hombres la vida divina. Por otra parte opina justamente que la carne movida por el Espíritu no hay que identificarla solo con la carne de la Palabra de Dios ("The eucharistic Gift", 168).

${ }^{22}$ San Agustín distingue entre el quomodo y el quisnam modus $(26,15)$; el quomodo y el quid $(26,18)$. 
la del cuerpo y la del espíritu ${ }^{23}$, pero mientras el primer alimento no la garantiza para siempre, el segundo sí: quien lo come tiene la vida eterna $(26,15)$, provisionalmente solo para el espíritu y, a la postre, también para el cuerpo $(26,16.20)$.

Cuestión trascendente es saber cómo se come efectivamente la carne y se bebe la sangre de Jesucristo, es decir, cuándo se da ese comer y ese beber. La cuestión es esencial porque lo que está en juego es el obtener la vida eterna, vinculada a esa doble acción. Como cabía esperar, el predicador no arriesga una opinión personal, partiendo de que la respuesta tiene que hallarse en las mismas palabras de Jesús. Y efectivamente la encuentra en estas palabras: Quien come mi carne y bebe mi sangre permanece en mí y yo en él (Jn 6,56). El haber asociado la respuesta a la cuestión a las palabras de Jesús tiene como consecuencia una forma peculiar de entender el modo: no es referido a la manera, sino al efecto. Se come la carne y se bebe la sangre del Señor cuando produce determinado efecto; en concreto, cuando el resultado es la permanencia recíproca de Jesucristo y de quien come su carne y bebe su sangre 24 . Por otra parte, el haber interpretado Jn 6,56 como la respuesta a la cuestión del cómo, implica que propiamente no es el fiel quien recibe a Cristo, sino Cristo quien acoge al fiel y le otorga una integración más plena en su cuerpo. Esa permanencia en él de que habla Jesús es la que garantiza la obtención de la vida, puesto que él mismo es la Vida $(J n 1,1 ; 6,48)$ y no da sino lo que él es $(27,9)$. Como condición para ello el predicador requiere aquí solo la limpieza moral25.

23 Cf. Berrouard, Marie-François, "Necessite de l'eucharistie pour la vie éternelle", en Homélies, Bibliothèque Augustinienne. Oeuvres de Saint Augustin 72, Paris 1977, 815-817, note complementaire 60.

24 Burns, James Patout, "The Eucharist as the Foundation of Christian Unity in North African Theology", en Augustinian Studies 32 (2001) 1-23, comenta: "comer la carne y beber la sangre de Cristo significa habitar en Cristo, un acto espiritual, más que carnal" (12), excluyendo por ello el realismo eucarístico y aceptando el simbolismo. Pero el estudioso no tiene en cuenta que san Agustín está hablando del efecto que produce, de la virtus del sacramento, no de la realidad (res). Tampoco tiene en cuenta el in crescendo que señalamos en la interpretación del texto de Jn 6,56. En esta primera interpretación el santo no alude para nada al cuerpo eclesial de Cristo, bien presente en las otras tres apariciones del pasaje evangélico, como indicando que el primer fruto de la eucaristía es la relación personal con Cristo, que luego es avalada con la permanencia en su cuerpo. Por otra parte, es cierto que san Agustín, siguiendo a san Pablo, presenta a la Iglesia como cuerpo de Cristo, pero no como su "cuerpo y sangre". Por último, no ha de privarse de su valor al posesivo "de Cristo" referido a la carne y a la sangre.

25 En otros textos, como se verá, incluirá una condición eclesial. 
Comer la carne y beber la sangre de Cristo efectivamente implica, pues, una permanencia. El término es importante aquí. Igual que el alimento ordinario no otorga la vida temporal, sino que solo la mantiene $(26,15)$, así tampoco la carne y la sangre de Cristo otorgan la vida al espíritu, sino que se limitan a mantenerla, aunque en este último caso para siempre, al menos en principio. La vida se recibe por el bautismo y se mantiene por el sacramento del altar de Dios. Pero, aunque otorgada por el bautismo, tiene su origen en Cristo y la conserva quien se alimenta de él -pan vivo (Jn 6,51)-comiendo su carne y bebiendo su sangre. El santo no entra en disquisiciones teológicas; se queda con el significado inmediato de las palabras de Jesús. Quien efectivamente come su carne y bebe su sangre permanece en él que, siendo la Vida, le mantiene en vida $(26,18)^{26}$.

Al hilo del texto de san Juan (Jn 6,56), el paso siguiente de san Agustín es mostrar la cadena trinitaria de la vida. Como el Hijo encarnado participa ${ }^{27}$ de la vida del Padre, así el fiel participa del Hijo, participación significada en el comer y beber la carne y la sangre de Jesucristo, gracias a la unidad de su cuerpo y de su sangre. Aquí vuelve a aparecer la idea de la unidad del cuerpo y de la sangre de Cristo ${ }^{28}$, modo de expresar que Jesucristo está vivo en cuanto partícipe de la vida del Padre, no descuartizado, y que de su vida participa el que come su carne y bebe su sangre. La consecuencia (ergo) es que quien come la una y bebe la otra sigue en vida ${ }^{29}$ por él (propter ipsum) al comerlo, esto es, al recibirlo a él, Vida eterna $(26,19)$.

Ya al término del discurso Jesucristo preguntó a los Doce, que se mantuvieron fieles a él, si también ellos querían irse. Las palabras con que Pedro respondió en nombre de todos Tú tienes palabras de vida eter$n a(\mathrm{Jn} 6,68)$ dan pie al predicador para recalcar, una vez más, que en el sacramento del altar los fieles no reciben otra cosa, sino lo que Cristo es, la Vida eterna: «tú eres la vida eterna misma y en tu carne y sangre no das sino lo que eres» $(27,9)^{30}$. Como Pablo hablaba de alimento y bebida

\footnotetext{
26 Hasta podía pensarse en una cadena de transmisión de la vida: La Palabra que era Vida (Jn 1,4) dio la vida eterna a la carne asumida por él (en concreto) $(26,10)$, y la carne asumida por la Palabra la trasmite a quien se alimenta de ella.

27 La participación es un concepto fundamental en la metafísica platónica, de la que Agustín hizo uso a lo largo de su vida, siempre que ello no implicaba oponerse a los contenidos de la fe.

28 Antes apareció en Tratado 26,15.

29 Damos al presente el sentido de duración que tiene en la lengua latina, recogiendo la idea del verbo permanecer.

30 Kilmartin comenta: "En efecto, Pedro, en cuanto representante de la iglesia creyente, dice esto: Cristo no otorga en su cuerpo del que él es cabeza, es decir, 'en su carne y sangre', sino lo que vosotros sois" ("The eucharistic Gift, 177). Pero esta identificación
} 
espiritual, refiriéndose a Cristo (1 Cor 10,1-4) (26,12), así también Jesús habla de su carne y de su sangre, en vez de hablar directamente de sí. Como Pablo pensaba en lo que llegaba a los judíos en el desierto, así Jesús piensa en lo que da a los fieles.

En lo que precede hemos expuesto el lado positivo de la realidad, pero el santo es consciente de que hay otro negativo con que amenaza el Apóstol: el peligro de comer y beber la propia condena (1 Cor 11,27.29). Eso implica que la obtención de la vida eterna no está asegurada por el solo hecho de recibir el sacramento del altar. A esta realidad hace referencia el predicador en dos textos, sirviéndose de la terminología habitual en él -sacramento y realidad (res)-. En el primero sostiene que unos toman el sacramento -por tanto, no solo el signo visible sino también la (res) ${ }^{31}$ - para la vida, y otros para su perdición, mientras que la realidad (res) del mismo sirve de vida a todo hombre que participa de él y a ninguno para su perdición $(26,15)$. Aquí el predicador actúa como exegeta, manteniéndose fiel al texto. No habla, por ejemplo, de condenación, sino de vida. Al respecto ha de tenerse en cuenta que la realidad (res) aquí contemplada es «la unidad del cuerpo y de la sangre de Cristo» que, como ya indicamos antes, cabe interpretar como una inferencia, con la mente puesta en los escépticos judíos, del comer la carne y beber la sangre -las dos cosas unidas- que otorga la vida eterna (Jn 6,54). En otros términos, como referencia al Cristo vivo, no descuartizado, como pensaban ellos. La diferencia que, en cuanto al resultado de la acción de comer su carne y beber su sangre, establece entre el sacramento y la realidad (res), se puede entender desde lo afirmado sobre el maná: que para unos significó la muerte y para otros la vida, estando la diferencia en que unos entendieron debidamente el sacramento y otros no -bajo el signo sacramental unos percibieron la realidad (res) oculta, otros no- $(26,11)$. En el caso presente, la realidad (res), es decir, la carne y sangre de Cristo vivo, aporta siempre vida; en cambio, el sacramento -el signo sacramental con la realidad (res)- aporta vida a quien lo recibe entendiendo lo que recibe; en caso contrario, lo que aporta es destrucción.

En otro texto san Agustín habla de comer y beber para propia condena $^{32}$ la realidad (res) tan grande del sacramento del altar ${ }^{33}$. Dos indica-

entre el cuerpo del que Cristo es cabeza y la carne y sangre de Cristo no aparece en el texto agustiniano. Como tampoco aparece "sino lo que vosotros sois", pues el predicador se dirige a Jesucristo: la vida eterna que es él (ibid.).

${ }^{31}$ De lo contrario no se entendería que el simple comer pan y beber vino produzca en unos la vida (eterna) y en otros su destrucción.

32 Ya en Tratado 26,11 el predicador había advertido sobre los muchos que mueren por recibir de forma indebida el sacramento del altar. 
dores revelan esa situación: uno que precede la acción de comer la carne y de beber la sangre de Cristo -la recepción del sacramento sin las condiciones morales adecuadas-, y otro que la sigue -el que no se produzca esa permanencia recíproca entre quien las recibe y Jesucristo- $(26,18)^{34}$. Pero, ¿cuál es el criterio para saber si efectivamente se ha comido la carne y bebido la sangre de Jesucristo? La respuesta la daremos de inmediato; antes concluimos lo referente a la vida eterna.

Al hilo de la segunda parte de Jn 6,54, san Agustín entiende que esa vida eterna, fruto de comer la carne y beber la sangre de Jesucristo, en el hombre ahora la posee solo su espíritu, aunque al final la poseerá también su cuerpo $(26,16)$. La continuación de las palabras de Jesús $($ Jn 6,55) dan pie al predicador para abundar en la idea de la vida eterna: solo la carne y sangre de Cristo eliminan toda hambre y toda sed, al hacer inmortales e incorruptibles a quienes las toman, como inmortal e incorruptible es la sociedad de los santos, que conoce la paz y unidad plenas y $\operatorname{perfectas}^{35}(26,17)$.

c) La prueba de que se permanece en Cristo: la participación en el Espíritu Santo (Jn 6,63)

Anteriormente dejamos abierta la pregunta sobre cómo se puede saber si se da o no se da esa permanencia recíproca entre quien participa del altar y Cristo, que certifica que se ha comido su carne y bebido su sangre cuyo efecto es la obtención de la vida eterna.

Responderla nos lleva de nuevo a la interpretación que ofrece el predicador de Jn 6,56, pero ahora con más detenimiento. En el texto -repetimos- encontraba el predicador de Hipona el criterio para saber si realmente se ha comido la carne y se ha bebido la sangre de Cristo, condición para obtener la vida eterna. Un primer dato llamativo es que se ocupa del mismo hasta cuatro veces: una en el Tratado 26 y tres en el Tratado 27. Un segundo

33 Con "sacramento" aquí no puede referirse solo a los signos sacramentales, el pan y el vino, porque del solo recibirlos a ellos no puede producirse un efecto negativo tan grande como es la propia condena. Lo lógico es pensar que entiende por "sacramento" el signo, perceptible por los ojos, en cuanto inseparable de su realidad (res) que le constituye en cuanto tal. Esa realidad (res) tan grande esa la carne y sangre de Cristo, es decir, Cristo mismo.

34 Todo lo dicho en este apartado presupone la presencia real de Cristo en el sacramento del altar. Si en él se recibe la vida y la vida es Cristo, en ella se recibe a Cristo. Por otra parte, si recibiéndola debidamente se permanece en Cristo y Cristo en quien la recibe, solo puede ser porque ya existía esa presencia recíproca.

35 A diferencia de lo que pasaba entre los judíos que litigaban entre sí. 
dato, no menos significativo, es la evolución que se percibe en el paso de un comentario a otro, de modo que se puede hablar de una interpretación in crescendo. La primera vez se limita a afirmar que se come la carne y se bebe la sangre de Cristo efectivamente si el resultado es la permanencia de quien la come y la bebe en Cristo y de Cristo en él, y la exigencia de unas condiciones morales $(26,18)$. Queda la impresión de que el santo aquí quiere poner de relieve únicamente la relación personal con Cristo, en sí mismo Vida (Jn 1,4) y para los hombres pan de vida (Jn 6,48) ${ }^{36}$. La segunda vez se ocupa del texto al comienzo mismo del Tratado 27. Después de señalar la oportunidad de un sermón sobre el cuerpo del Señor ${ }^{37}$, debido a que lo predicaba en la fiesta del mártir san Lorenzo, insiste en la idea del texto anterior pero ahora saca de ella una conclusión (ergo): con esas palabras cargadas de significado (mysticis) el Señor nos enseñó y exhortó a que sigamos $^{38}$ en su cuerpo bajo él como cabeza, comiendo su carne y no abandonando la unidad del mismo $(27,1)^{39}$. En otros términos, el santo sostiene que permanecer en Cristo exige permanecer en su cuerpo; que no basta la relación puramente personal con él, si no incluye también la relación con sus otros miembros. De una realidad concluye a otra: de la permanencia en Cristo pasa a la permanencia en su cuerpo eclesial, todo ello en virtud de la realidad teológica del Christus totus, aludida en las mismas palabras del santo. Por tercera vez se ocupa del texto a propósito de las palabras de Jesús: Las palabras que os he dicho son Espíritu y son Vida (Jn 6,63b). En su comentario, el predicador retoma las dos ideas ya señaladas: que, en el comer su carne y beber su sangre el Señor nos encarece que permanezcamos en él y él en nosotros, y que nuestra permanencia en él va asociada a la condición de ser miembros suyos, pero aquí añade todavía una más: lo uno y lo otro es obra del Espíritu Santo. No solo lo afirma, sino que lo argumenta: el Espíritu Santo derrama la caridad (cf. Rom 5,5) que produce la unidad, trabando entre sí los miembros del Cuerpo de Cristo. Estar en Cristo im-

${ }^{36}$ Salvo que esa brevedad obedezca a que el obispo consideraba que llevaba demasiado tiempo hablando ya y no quería alargarse aún más, algo que nos parece poco probable porque siempre podía haber anticipado la idea, que luego desarrollaría más detenidamente en el Tratado siguiente.

37 Kilmartin considera que el significado del "cuerpo del Señor" aquí es ambiguo, argumentando que en Tratado 27,11 aparece por dos veces significado su cuerpo eclesial ("The eucharistic Gift", 163, n.6). Aunque este último dato es cierto, no admite comparación con la mención aquí del cuerpo del Señor, puesto que de él se afirma que lo iba a dar a comer con vistas a la vida eterna.

$38 \mathrm{Al}$ presente simus hay que darle un significado de presente continuo de "seguir estando", que refleje el "permanecer" de Jn 6,56.

39 Kilmartin no señala ninguna diferencia entre la interpretación dada aquí y la dada en Tratado 26,18 ("The eucharistic Gift", 164), pasando por alto este añadido. 
plica poseer su Espíritu que, a su vez, mantiene en Cristo porque, mediante el don de la caridad, le mantiene dentro de su cuerpo, inseparable de él. Señal de haber recibido a Cristo es haber recibido el Espíritu de Cristo y, al revés, haber recibido el Espíritu de Cristo es prueba de haber recibido a Cristo, porque el Espíritu de que se trata es el Espíritu de Cristo ya glorificado. La conclusión (ergo) del predicador es que es el Espíritu el que vivifica (Jn 6,63a), dado que es el espíritu el que hace que tengan vida los miembros que forman parte del cuerpo que vivifica. Desde la realidad antropológica que le sirve de comparación se entiende perfectamente que separarse del cuerpo de Cristo implica no ser miembro suyo y no ser animado mediante su Espíritu ${ }^{40}$. Dicho a la inversa: no poseer el Espíritu de Cristo implica no pertenecer a Cristo (Rom 8,9). El Espíritu y la vida van inseparablemente unidos (Jn 6,63b). Cuanto ha dicho Jesús sobre su carne y su sangre como fuente de vida presupone esa referencia al Espíritu y a la Vida. El texto aparece por cuarta vez en la síntesis que ofrece ya a punto de terminar el Tratado 27 donde, en coherencia con esa voluntad sintética, recoge también el conjunto de aspectos previamente considerados, uno de ellos que se come la carne y se bebe la sangre de Cristo si se produce la permanencia repetidamente señalada. Según el predicador, todo lo dicho por el Señor, incluido lo referente a tal permanencia, debe conducir a que nadie coma la carne y beba la sangre de Jesucristo solo en sacramento, como muchos malos, sino a que se coma y se beba en modo de llegar a participar en el Espíritu, cuya consecuencia será la de permanecer como miembro en el cuerpo del Señor, siendo animado mediante su Espíritu $(27,11)^{41}$. Las ideas que ha expuesto el predicador son, pues, las siguientes: quien recibe la carne y la sangre de Cristo ha de permanecer en él, en la condición de miembro suyo, participando de su Espíritu, mediante el cual anima a su cuerpo. Al predicador no le basta recibir solo el sacramento -la realidad (res) oculta bajo el signo sacramental-, si esa recepción no conlleva también participar del Espíritu. Este planteamiento nos ubica en la polémica con los cismáticos que, compartiendo la fe en el sacramento, no se beneficiaban de su virtud (virtus), de su efecto: al hallarse fuera del cuerpo de Cristo manifestaban que la recepción de su carne y de su sangre no les aportaba la vida porque carecían del Espíritu que les unía a la fuente de la vida, Cristo.

${ }^{40}$ Vegetari Spiritu: significativo el cambio de verbo (vegetare en vez de vivificare) y de función sintáctica del Espíritu (de sujeto de verbo a complemento circunstancial). Más adelante volveremos sobre este particular.

41 Cf. Berrouard, Marie-François, "L'Euchariste sacrement de communion par la participation à l'Esprit du Christ", en Bibliothèque Augustinienne. Oeuvres de Saint Augustin 72, Paris 1977, 830-832, nota complementaria 71. 
Las ideas que el obispo de Hipona ha ido desgranando en relación con Jn 6,56, habían aparecido previamente en Tratado 26,1342. El texto desarrolla con más extensión que en Tratado 27,6 el dato antropológico que le sirve de comparación y pone mayor énfasis en que el Espíritu de Cristo solo se puede poseer en el Cuerpo (eclesial) de Cristo. Es este cuerpo eclesial de Cristo, no su cuerpo sacramental, el presentado como sacramento de piedad, como signo de unidad y como vínculo de caridad ${ }^{43}$. Él es sacramento del amor de los fieles íntimamente unidos a Cristo; él es signo, es decir, expresión de la unidad de los fieles; él es vínculo de caridad porque en él se encuentran todos unidos. La reflexión arranca de las palabras de Jesús en las que habla de su carne dada por la vida del mundo (Jn 6,51). Quien desea esa vida, sabe que solo la puede encontrar en el cuerpo (eclesial) de Cristo en donde la recibe del Espíritu de Cristo ${ }^{44}$.

¿Por qué esta amplia reflexión sobre el cuerpo eclesial del Señor en Tratado 26,13, en que comienza la exposición de la virtud (virtus) del sacramento del altar? Una respuesta se deduce del texto evangélico: Nada más oír que Jesús iba a dar su carne por la vida del mundo, los judíos comenzaron a discutir entre sí (Jn 6,51). Mal comienzo - parece pensar san Agustín- para entender las palabras de Jesús que prometen la vida $(26,14)^{45}$.

42 Es cierto que no utiliza el verbo permanecer, porque aún no ha llegado a las palabras de Jesús (Jn 6,56) que justifican el empleo del verbo. La idea está presupuesta en el "no descuidar ser cuerpo de Cristo". M.-Fr. Berrouard interpreta que en la frase: "Los fieles conocen el cuerpo de Cristo si no descuidan ser cuerpo de Cristo" el primer cuerpo se refiere al cuerpo eucarístico de Cristo y el segundo a su cuerpo eclesial (Homélies sur l'évangile de Saint Jean. XVII-XXXIII, Oeuvres de Saint Augustin, BA 72, París 1977, 516, n.125. En nuestra opinión en los dos casos se refiere al cuerpo eclesial. Lo que el predicador quiere decir es que el conocimiento del cuerpo eclesial solo tiene lugar desde dentro del mismo, en línea con la afirmación posterior de que solo comen y beben realmente el cuerpo y sangre de Cristo quienes permanecen en Cristo y en su cuerpo.

43 Contra lo habitual que es referir las palabras a la eucaristía. Cf. Berrouard, Marie-François, "O sacramentum pietatis, o signum unitatis, o vinculum caritatis", en Homélies, note complementaire 60, BA 72, 814-815.

44 También este texto es interpretado como aval del simbolismo eucarístico de san Agustín (Burns, "The Eucharist", 12-13). Pero aquí el santo está indicando dónde se puede encontrar la vida que Jesucristo vincula al hecho de comer su carne. Por tanto, no está hablando de la realidad (res) del sacramento, sino de su virtus (cf. 26,11.12). Cosa distinta es el papel que asigna al Espíritu en la otorgación de esa vida, vida que es Cristo $(27,9)$. Estamos de acuerdo con la afirmación del autor: "To share the reality and not just the sacrament of the eucharist one must be joined into that invisible unity and thus become the body of Christ" (p. 13). El problema es que aquí el autor está jugando solo con dos categorías de la teología sacramentaria agustiniana, el sacramentum y la res, mientras que san Agustín funciona con tres, es decir, añadiendo la virtus. Es la virtus, no la res la que el santo parece tener en mente en el texto de Tratado 26,13.

45 Ese litigar, dice el santo, era fruto de que ni entendían ni querían comer el pan de la concordia. Kilmartin opina que el pan de la concordia es el cuerpo eclesial del Señor 
Otra respuesta guarda relación con lo anterior: la vida que otorga la carne y la sangre de Cristo no puede recibirse fuera de su cuerpo eclesial. Permanecer en el cuerpo eclesial es la prueba de permanecer en Cristo mismo, fuente de la vida, dada la unidad inseparable entre él y su cuerpo.

Todavía queda un texto agustiniano por considerar a propósito de Jn 6,54 (Quien come mi carne y bebe mi sangre tiene vida eterna). Tras repetir lo dicho por Jesús, es decir, que quien come el alimento que es el cuerpo y la sangre del Señor tiene la vida eterna, saca una conclusión que ha sido interpretada como expresión clara de que Agustín defiende una presencia simbólica, no real, de Cristo en la Eucaristía. En su literalidad es esta: «Así, pues, quiere que este alimento y esta bebida se entienda como la sociedad del cuerpo y de sus miembros, cosa que es la santa Iglesia en sus predestinados, llamados, justificados, santos glorificados y fieles» $(26,15)$. Si no se tiene en cuenta que se trata de una conclusión (itaque) de lo dicho inmediatamente antes y no se presta atención a que el santo no habla del cuerpo y sangre de Cristo, sino solo de su condición de alimento y bebida, es fácil concluir que para el Santo el cuerpo y sangre de Cristo son solo un símbolo de la Iglesia. A nuestro parecer, lo que Agustín quiere decir es que lo afirmado anteriormente, esto es, que el alimento que da Cristo otorga la vida eterna, lo entenderá quien ponga sus ojos en la Iglesia santa, en su dimensión escatológica. A ella conduce la participación en el altar del Señor. Por otra parte, si la carne y la sangre de Cristo producen como efecto la vida eterna, es que se hallan unidas, sin el despedazamiento que presuponían los judíos. Esta unidad del cuerpo y sangre de Cristo, Cristo mismo, Vida eterna, que por eso mismo puede otorgarla a quienes la reciben $(27,9)$, es la realidad (res) propia del sacramento del altar $(26,15)$.

\section{b) El exégeta, el teólogo y el pastor}

Es evidente que el aspecto del cuerpo eclesial de Cristo es el más desarrollado en la exposición agustiniana del discurso de Jesús sobre el

("The Eucharistic Gift", 180, n. 8), pero no hay que confundir la realidad (res) con la virtud (virtus). Pensar que el predicador reproche a los judíos en aquel momento en Cafarnaún rehusar pertenecer al cuerpo eclesial de Cristo, parece anacrónico. Según el texto, cuerpo eclesial de Cristo no lo constituye el pan de la concordia mismo, sino quienes comen de él. Por otra parte, en la mente del predicador parecen estar los donatistas. Si ellos mantenían su litigio con los católicos era porque ni entendían que la eucaristía era el pan de la concordia y, por ello, aunque la recibían, no lo recibían como pan de concordia. De ahí que persistieran en la división. 
pan de vida. Pero no hay que ver en él la realidad (res) del sacramento del altar, sino su virtud (virtus). La afirmación, no obstante, requiere ser matizada. Desde el punto de vista exegético, es decir, de lo que cabe deducir del tenor literal de los textos comentados, la virtud (virtus) de la eucaristía no puede ser otra que la vida (eterna). Y así lo ha puesto de relieve san Agustín como se ha señalado. Ahora bien, la virtud (virtus) es inseparable de la realidad (res). Por tanto, si, como hemos señalado poco ha, esa vida (eterna) es fruto de recibir la carne y la sangre de Cristo unidas, es decir, sin ningún previo descuartizamiento, la realidad (res) no puede ser sino la carne y sangre de Cristo, es decir, Cristo mismo. Recibir la vida que es Cristo significa recibir a Cristo. Recibir la vida eterna es inseparable de recibir la Vida eterna. Sin realismo eucarístico -ya explicitado en Tratado 26,11-12-, no se explica esa virtud (virtus).

Pero hasta en función de exegeta san Agustín se manifiesta como teólogo. Una vez admitido que la vida se recibe de Cristo, y que para recibirla hay que permanecer en él, la cuestión es cómo saber que se da esa permanencia. La respuesta del obispo de Hipona pasa por el concepto teológico, tan suyo, del Christus totus: permanece en Cristo quien es miembro de Cristo, y es miembro de Cristo quien forma parte de su cuerpo, la Iglesia, en virtud de la inseparabilidad de la cabeza y del cuerpo en todo organismo vivo. La realidad personal la manifiesta la realidad social: no hay permanencia en Cristo si no se da también la permanencia en el cuerpo de Cristo. Se requiere, pues, ser miembro de su cuerpo, pero -advierte el predicador- no un miembro cualquiera: no un miembro que merezca ser amputado -referencia a la condición eclesial-, no un miembro deforme del que se deba avergonzar -referencia a la condición moral-, sino un miembro bello, proporcionado, sano $(26,13)$; un miembro vivo porque la caridad que recibe del Espíritu Santo (Rom 5,5) le mantiene unido al resto de los miembros que reciben la vida de la Cabeza $(27,6)$. El Espíritu de Cristo da vida al fiel al mantenerle unido a Cristo para que reciba la vida de él, Vida en persona. Aunque algunos textos agustinianos puedan dejar la impresión contraria, propiamente hablando, el fiel no recibe la vida del Espíritu sino de Cristo. No obstante, el Espíritu posibilita que la reciba de Cristo al mantenerlo unido al cuerpo de Cristo mediante el don de la caridad.

Afirmar que san Agustín atribuye directamente al Espíritu el don de la vida sería ponerle contra el texto que comenta y contra la interpretación que hace de él. En el texto que comentaba él leía: Yo (Jesucristo) soy el pan de vida (Jn 6,48); este (Jesucristo) es el pan que ha descendido del cielo (Jn 
6,50), y Yo (Jesucristo) soy el pan vivo bajado del cielo (6,51). Por otra parte, él recalca la relación entre tener la vida eterna y el mismo Jesucristo: «Él mismo, la Vida eterna, dio también a la carne asumida la vida eterna» $(26,10)^{46}$. Si él, la Vida eterna, otorgó la vida eterna a la carne que asumió, quien recibe esa carne en el sacramento, recibe la vida también. Por último, un detalle filológico tomado de Tratado 27,6. Para explicar la permanencia en Cristo, el predicador ha enlazado estas ideas: el Espíritu difunde en los corazones la caridad, que produce la unidad, manifestada en la trabazón de los miembros del cuerpo de Cristo. Y concluye (ergo): El Espíritu es quien vivifica (Jn 6,63), pues (enim) es el espíritu el que hace que estén vivos ( $f a$ cit viva) los miembros. Pero esta explicación parece pertenecer ya al ejemplo que le sirve de comparación, la realidad humana. El ejemplo muestra que el espíritu hace, sí, que los miembros estén vivos (facit viva), pero solo a los que anima él mismo (vegetat ipse spiritus). El espíritu del hombre solo vivifica (vivificat) a los miembros que radican en su carne; uno amputado ya no recibe la vida de su alma (vivificatur ex anima tua). El empleo aquí del verbo en pasiva (vivificatur) con su complemento de origen (ex anima $t u a^{47}$ ) ilumina el sentido del verbo en activa (vivificat): aunque se hable de que vivifica el espíritu, quien en realidad vivifica es Dios que lo hace a partir del alma. Cuando pasa del ejemplo antropológico a la realidad teológica, el santo renuncia a emplear el verbo «vivificar», que sustituye por «animar» (uegetare), y renuncia a contemplar al Espíritu como sujeto, prefiriendo asignarle la función de complemento circunstancial (non vegetatur Spiritu eius) $(27,6)$. De idéntica construcción gramatical se sirve en la síntesis del Tratado 27,11 , en que exhorta a no comer la carne y la sangre de Cristo solo en sacramento, sino en modo de llegar a participar del Espíritu para así permanecer en su cuerpo como miembros y ser animados mediante su Espíritu (eius Spiritu vegetemur). Como el santo utiliza habitualmente la preposición $a$ con ablativo cuando el Espíritu santo cumple la función de complemento agente ${ }^{48}$, el renunciar a ella en estos casos permite suponer que le asigna una función instrumental ${ }^{49}$. Advirtiendo que, en fidelidad al texto que está comentando, no puede desvincular de Cristo el don de la vida, el santo asume

46 Aunque en este caso no hablaba de comer su carne y beber su sangre, sino de creer en él: En verdad os digo: quien cree en mí tiene vida eterna (Jn 6,48).

${ }^{47}$ En el mismo pasaje el santo identifica alma y espíritu.

48 Solo algunos ejemplos: "et cum adoras illum, ne cogitatione remaneas in carne, et a Spiritu non uiuificeris" (en. Ps. 98,8); "arguitur a Spiritu Sancto mundus" (Io. eu. tr. 95,4); "caritas, quae inspirata est intus a Spiritu Sancto" ( ep. Io. tr. 8,1).

${ }^{49}$ Más detalladamente en Luis VizCAíno, Pío de, "El 'alma' de la Iglesia y el 'alma de la Iglesia’ según san Agustín”, en Revista Agustiniana 57 (2016) 61-99, sobre todo 74-79. 
que a él le corresponde la función de sujeto, asignando al Espíritu la de medio. Es Cristo quien otorga la vida, pero lo hace por medio del Espíritu. Es la concepción que parece subyacer a este texto de un sermón: "seamos todos miembros en un único cuerpo; recibamos la vida de nuestra cabeza" 50 . La vida se recibe de Cristo, pero condición para recibirla de él es pertenecer a su cuerpo, siendo función del Espíritu mantener al que come la carne y la sangre de Cristo dentro del cuerpo de Cristo, mediante el don de la caridad.

En realidad este sería solo un segundo momento, siendo el primero el correspondiente a la integración inicial en el cuerpo de Cristo. Así ha de entenderse, si no se olvida que, según las palabras se Jesús, come la carne y bebe la sangre de Cristo quien permanece en él (Jn 6,56). Si permanece, es que ya está en él. En el plano sacramental eso quiere decir que el sacramento del bautismo precede al de la eucaristía. Si en el segundo momento el Espíritu mantiene al fiel en el cuerpo de Cristo -hace que permanezca en Cristo-, en el primero produce la inicial integración en el cuerpo de Cristo, al unirlo, mediante la caridad, don suyo, a Cristo y a los demás miembros de Cristo. Desde ambas perspectivas, la vida pasa al fiel por el Espíritu pero tiene su origen en Cristo. Lo dicho se puede resumir de esta manera: No cabe recibir la vida, virtud (virtus) del sacramento del altar, fuera de Cristo, pan de vida (Jn 6,48). Como no cabe permanecer en Cristo, si no es por obra del Espíritu Santo -Espíritu de Cristo-, es legítimo afirmar que el Espíritu otorga la vida. Pero tal legitimidad se sostiene sobre la aceptación de todos estos presupuestos: solo quien está en Cristo puede recibir el Espíritu de Cristo; solo quien está ya en Cristo -por el bautismo- puede permanecer en Cristo -por la Eucaristía-; solo cabe permanecer en Cristo en condición de miembro de Cristo; solo cabe ser miembro de Cristo en unión con los demás miembros de Cristo -en virtud de la unidad del cuerpo-; solo es posible mantener la unidad con los demás miembros de Cristo si se posee la caridad, don del Espíritu de Cristo.

Al exponer el discurso de Jesús sobre el pan de vida, san Agustín actúa no solo como exegeta y teólogo, sino también como pastor. Él no hablaba para eruditos del futuro, sino para los fieles de la comunidad a la que servía, en su contexto concreto. En el año 414, fecha en que fueron predicados los Tratados 26 y 27, san Agustín tenía ante sí dos tormentas con ciclogénesis opuestas: el pelagianismo, de reciente formación, y el donatismo, en vías de desaparición. El predicador nunca los menciona

\footnotetext{
50 En. Ps. 32,2,2,28.
} 
por su nombre en ninguno de los dos Tratados pero sin duda los tenía presentes en su mente. La afirmación es más clara referida a los donatistas $^{51}$ que a los pelagianos. A estos esperaba aún reconducirlos al buen camino; aquellos habían lacerado a la Iglesia durante todo un siglo y a él hasta le habían tendido trampas, mortales en la intención, y durante años se habían constituido en objetivo particular de su actividad pastoral. El predicador tenía que desactivar a la una y a la otra con recursos tomados de la Escritura, luego adaptados por su propia reflexión teológica. A la autosuficiencia de los pelagianos el exegeta respondía dejando clara la necesidad de la eucaristía $(26,15)$ y afirmando que la vida se recibe de Cristo, él mismo Vida $(27,9)$. Frente a la autoexclusión de los donatistas, el teólogo puso de relieve que la vida (eterna) que otorga Cristo no se puede recibir fuera del cuerpo eclesial de Cristo, lugar donde actúa el Espíritu de Cristo, por medio del cual la otorga. Que no cabe esperar recibir la vida que otorga la acción de comer la carne y de beber la sangre de Cristo fuera del cuerpo eclesial de Cristo lo dejó entender Cristo al elegir como elementos eucarísticos el pan y el vino: «Por eso ciertamente, como algunos hombres de Dios lo han entendido antes que nosotros, nuestro Señor Jesucristo confió su cuerpo y su sangre mediante cosas que, de muchas, se reducen a cierta unidad. En efecto, uno se constituye en unidad a partir de muchos granos; el otro confluye a la unidad a partir de muchas uvas» $(26,17)$.

\section{Conclusión}

A punto de concluir estas páginas, reiteramos lo ya repetidamente afirmado. En su comentario de Jn 6,51-71 en los Tratados 26 y 27, el obispo de Hipona expone cuál es la virtud (virtus) del sacramento del altar: la vida eterna, ajustándose así al contenido de las palabras de Jesús. Él ha interpretado que tales palabras había que leerlas en clave sacramental y para ello ha creado el marco adecuado en el comentario a los versículos previos (Jn 6,48-49). Presentó el maná como un sacramento, recurriendo a 1 Cor 10,1-4 para descubrir la realidad (res), puesto que en Jn 6,49 solo encontraba el signo visible -el maná- y la virtud (virtus) -la vida ${ }^{52}$. Simultáneamente establece la comparación con el sacramento del altar, mostrando divergencias y coincidencias. Entre estas cuenta la identidad

\footnotetext{
51 Cf. Burns, "The Eucharist", 14-17.

52 Aunque en formulación negativa -murieron- la referencia es la vida.
} 
de virtud (virtus). De ahí parte la interpretación del santo de las siguientes palabras de Jesús, comenzando en Jn 6,51. Y, si ello es así, no cabe interpretar en clave de simbolismo sino de realismo eucarístico el comentario agustiniano ${ }^{53}$.

Fueron muchos los cursos en que D. Senén Vidal expuso a los alumnos de nuestro Estudio Teológico el evangelio según san Juan. Aunque la perspectiva desde la que me he acercado aquí al cuarto evangelio sea muy diferente de la suya, valgan estas páginas para expresar mi recuerdo agradecido.

53 Por tanto no compartimos la conclusión de J. P. Burns: "Así, pues, la comprensión de Agustín de la presencia de Cristo en la eucaristía es totalmente clara. El pan y el vino son signos visibles de una realidad invisible, el sacramento del cuerpo eclesial de Cristo. Participar de la realidad invisible mediante el comer y el beber visibles significa pertenecer al cuerpo de Cristo participando en la unidad de amor. El cuerpo cuya alma es el Espíritu Santo no es el cuerpo celeste, sino el cuerpo eclesial de Cristo. Mediante el don de la caridad, el Espíritu une los miembros de Cristo en el cuerpo de amor y realiza en ellos todas las buenas obras" (BuRns, James Patout, "The Eucharist", 14). El problema del autor, a nuestro juicio, es que buscó en el texto agustiniano estudiado lo que el santo no pretendía ofrecer en él. El subrayado es nuestro. 